\title{
PENGARUH PEOPLE, PROCESS, DAN PHYSICAL EVIDENCE TERHADAP KEPUASAN KONSUMEN PT KERETA COMMUTER INDONESIA (KCI)
}

\author{
Dendi Yulis Setianto1*, Nur Hidayatullah', Ajat Sudrajat1 \\ ${ }^{1}$ Program Studi S1 Manajemen, Fakultas Ekonomi dan Bisnis, Universitas Singaperbangsa Karawang, \\ Indonesia \\ *Email corresponding author: dendiyulis97@gmail.com
}

\begin{abstract}
Abstrak
Penelitian ini bertujuan untuk mengetahui pengaruh people, process, dan physical evidence terhadap kepuasan konsumen pengguna transportasi KRL Commuter Line. Responden dalam penelitian ini adalah konsumen yang pernah menggunakan transportasi KRL Commuter Line. Teknis Sampling yang digunakan pada penelitian ini adalah non-probability sampling dengan proporsional purposive sampling, jumlah responden dalam penelitian ini adalah 140 responden. Analisis data yang digunakan adalah analisis jalur. Berdasarkan hasil penelitian bahwa secara simultan menunjukkan bahwa people, process, dan physical evidence berpengaruh signifikan terhadap kepuasan konsumen dan secara parsial menunjukkan bahwa variable physical evidence secara signifikan paling berkontribusi dalam mempengaruhi kepuasan konsumen.
\end{abstract}

Kata Kunci: people, process, physical evidence, kepuasan konsumen, krl commuter line

\begin{abstract}
The aims of the research to investigate the influence of the people, process, and physical evidence on customer satisfaction of KRL Commuter Line transportation users. Respondents in this study are consumers who have used KRL Commuter Line transportation. The Sampling Technique used in this study is non-probability sampling with proportional purposive sampling. The number of respondents in this study was 140 respondents. Analysis of the data used is path analysis. Based on the results of the study shawed that simultaneously showed that people, process, and physical evidence significantly effect on customer satisfaction and partially showed that physical evidence variable significantly contributed most in influencing customer satisfaction.
\end{abstract}

Keywords: people, process, physical evidence, customer satisfaction, krl commuter line

\section{PENDAHULUAN}

Pada era globalisasi saat ini, pola konsumsi masyarakat telah berubah. Hal ini dilatarbelakangi karena adanya peningkatan perekonomian dan kemajuan teknologi. Seiring berkembangnya perekonomian dan meningkatnya pertumbuhan penduduk menyebabkan permintaan terhadap pelayanan jasa transportasi juga meningkat, sehingga semakin pesat perkembangan jasa pelayanan transportasi.

Transportasi diartikan sebagai alat pemindahan barang maaupun manusia dari suatu tempat ke tempat lain, dimana di dalamnya terdapat unsur pergerakan oleh mesin dan manusia. Transportasi memegang peranan sangat penting dalam pembangunan dan pengembangan infrastruktur wilayah perkotaan dan perdesaan yang mendukung kegiatan penting perekonomian masyarakat. Masyarakat tidak hanya terfokus pada kebutuhan konsumsi produk fisik, namun masyarakat juga membutuhkan konsumsi produk jasa yang timbul karena adanya kebutuhan akan pelayanan. Dewasa ini moda transportasi yang digunakan yaitu terdiri dari transportasi tradisional seperti gerobak sapi, unta, kuda, delman, becak, dan sepeda serta juga untuk transportasi modern seperti motor, mobil, kereta api, pesawat terbang, helikopter, dan kapal laut. Namun, saat ini penumpang mulai didominasi oleh 
generasi millennial, kaum yang mengutamakan keefektif dan keefesienan dalam menjalankan aktivitasnya.

Menurut Data Badan Pusat Statistik (BPS) mencatat jumlah pengguna jasa layanan kereta api pada 2017 mencapai 393,27 juta penumpang naik 11,78\% dibanding tahun sebelumnya. Jumlah tersebut terdiri dari penumpang di Jabodetabek 315,85 juta penumpang, kemudian Jawa (non Jabodetabek) 70,51 juta penumpang dan Sumatera sebanyak 6,91 juta penumpang. Penumpang KRL (Commuterline) di Jakarta dan sekitarnya masih mendominasi penumpang kereta di tanah air, yakni mencapai sekitar $80 \%$ penumpang kereta besi tersebut.

PT KAI Commuter Indonesia sebagai anak perusahaan dari PT Kereta Api Indonesia (Persero) yang bertanggung jawab menyediakan transportasi kereta api di wilayah Jakarta, Bogor, Depok, Tangerang, dan Bekasi (Jabodetabek) dan sekitarnya. Berdasarkan data PT Kereta Commuter Indonesia (KCI) jumlah penumpang KRL sepanjang 2017 mencapai 315,8 juta penumpang naik $12,55 \%$ dari sebelumnya. Jumlah tersebut sekitar 868 ribu/hari, sehingga dapat dibayangkan jika terjadi masalah terhadap moda transportasi umum tersebut. Untuk tahun ini, KCI menargetkan jumlah penumpang KRL akan meningkat menjadi 320 juta orang atau rata-rata 879 ribu/hari.Berdasarkan lintasannya, pada 2017 KRL terbanyak melayani penumpang di lintasan Depok-Bogor, yakni mencapai $69,95 \%$ dari total penumpang pada tahun lalu. Kemudian diikuti lintasan Bekasi-Cikarang sebesar 13,48\%, Serpong-Rangkasbitung 11,87\% dan Tangerang 4,72\% dari total penumpang KRL.

Peningkatan jumlah penumpang tiap tahunnya menunjukkan bahwa masyarakat sudah cerdas dalam memilih moda transportasi yang digunakan untuk menunjang aktivitasnya, namun dalam segi pelayanan kepada pengguna jasa juga harus pula diperhatikan agar terciptanya kepuasan penggunaan moda transportasi ini.Wijaya (2011:4) mengemukakan bahwa kepuasan konsumen dapat dicapai dengan memberikan kualitas yang baik. Oleh karena itu, perusahaan jasa harus berfokus pada kepuasan konsumen. Untuk dapat mengetahui pelayanan yang diinginkan, dibutuhkan, dan diharapkan oleh konsumen maka dilakukan penelitian konsumen.

Yamit (2013:74) mengemukakan bahwa pelaku bisnis tidak hanya bertujuan memenuhi kebutuhan pelanggan, tapi berusaha melakukan perbaikan terus menerus atas produk dan pelayanan untuk meningkatkan kepuasan pelanggan pada setiap lini produk dan pelayanan. Kemajuan teknologi dan informasi dimanfaatkan untuk meningkatkan pelayanan dan kepuasan pelanggan tersebut. Sebagai salah satu perusahaan yang bergerak di bidang jasa, PT KAI Commuter Indonesia (KCI) dalam memberikan kepuasan kepada pengguna jasa transportasi harus memerhatikan beberapa faktor di antaranya mengenai pelayanan people, process, dan physical evidence dari KRL Commuter Line tersebut.

People atau SDM yang professional dalam melayani setiap pengguna jasa transportasi ini juga sangat berpengaruh dalam memberiakan arahan, himbauan dan pelayanan agar setiap pengguna jasa mengerti akan aturan dan prosedur yang dijalankan dalam menggunakan moda transportasi KRL Commuter Line tersebut. Kemudian process yang dalam KRL Commuter Line juga perlu diperhatikan, diantaranya dalam hal e-ticketing yang dapat mempermudah konsumen dalam melakukan pembelian tiket menjadi lebih efektif dan efesien, ketepatan waktu kedatangan dan keberangkatan kereta. Selanjutnya mengenai physical evidence juga perlu menjadi perhatian khusus juga mengingat ini adalah fasilitas untuk meningkatkan kepuasan konsumen diantaranya penambahan gerbong kereta, menyediakan gerbong khusus wanita, perluasan kawasan parker, renovasi toilet dan musholla dan fasilitas-fasilitas lain demi menunjang kenyaman pengguna KRL Commuter Line.

Berdasarkan latar belakang tersebut tujuan penelitian ini adalah untuk mengetahui pengaruh people, process, dan physical evidence terhadap kepuasan konsumen pengguna transportasi KRL Commuter Line 


\section{TINJAUAN PUSTAKA DAN PERUMUSAN HIPOTESIS}

\section{People}

Menurut Lovelock $(2011 ; 48)$ people adalah individu yang memiliki keterampilan interpersonal dan sikap positif yang berinteraksi langsung dengan konsumen. Pendapat dari ahli lain menyatakan bahwa partisipan (People) adalah semua orang yang memainkan peranan dalam penyajian layanan yang dapat mempengaruhi persepsi konsumen (Zeithmal, Bitner dan Gremler, 2006, p.26).

Dalam penelitian ini petugas pada stasiun dan gerbong berperan aktif dalam memberikan pelayanan kepada konsumen selama melakukan pemakaian jasa transportasi KRL Commuter Line, faktor people ini berperan aktif dan bisa berpengaruh positif terhadap keputusan pembelian, seperti yang dikemukakan oleh Kotler (2009), semakin positif kinerja yang diberikan kepada konsumen, semakin baik pula dampaknya dalam melakukan keputusan pembelian.

\section{Process}

Zeithmal dalam Hurriyati (2005:64) adalah semua prosedur aktual, mekanisme dan aliran aktifitas yang digunakan untuk menyampaikan jasa. Semua kegiatan pekerjaan adalah bagian dari suatu proses. Proses ini dapat meliputi berbagai mekanisme yang ada, misalnya adanya mekanisme pelayanan, prosedur, jadwal kegiatan, serta rutinitas.

Menurut Philip Kotler (2006), proses disini adalah mencakup bagaimana cara perusahaan melayani permintaan tiap konsumennya. Mulai dari konsumen tersebut memesan (order) hingga akhirnya mereka mendapatkan apa yang mereka inginkan. Beberapa perusahaan tertentu biasanya memiliki cara yang unik dalam melayani konsumennya dan menarik konsumen agar menggunakan produknya. Berbeda dengan perusahaan milik pemerintah yang caranya sudah diatur untuk melayani masyarakat yang membutuhkan jasa tersebut agar timbul rasa kepuasan konsumen atau masyarakat atas fasilitas publik yang diberikan pemerintah. Maka dari itu, proses dalam pemasaran yang dimaksud disini adalah keseluruhan sistem yang berlangsung dalam penyelenggaraan dan menentukan kualitas mutu yang dapat memberikan kepuasan yang diharapkan oleh penggunanya.

\section{Physical Evidence}

Kotler (2011) adalah bukti yang dimiliki oleh penyedia jasa yang ditujukan kepada konsumen sebagai usulan nilai tambah konsumen. Bukti fisik adalah segala sesuatu baik keadaan, kondisi juga termasuk di dalamnya berupa suasana dari stasiun dan gerbong-gerbong KRL Commuter Line yang tersedia. Hal tersebut akan semakin memperkuat keberadaan jasa yang sangat dibutuhkan konsumen untuk bepergian dalam jangkauan lokasi yang cukup jauh dan akan mahal jika ditempuh dengan fasilitas alat transportasi lainnya. Karena dengan adanya fasilitas pendukung sebagai bukti fisik suatu penyedia jasa, maka konsumen akan lebih memilih menggunakan jasa yang ditawarkan tersebut daripada yang lain.

Hurriyati (2002), mengemukakan bahwa perusahaan melalui tenaga pemasarnya menggunakan tiga cara dalam mengelola bukti fisik yang strategis yaitu (1) An attention-creating medium perusahaan jasa melakukan differensiasi dengan pesaing dan membuat sarana fisik semenarik mungkin untuk menjaring pelanggan dari target pasarnya. (2) As a massage-creating medium menggunakan simbol atau isyarat untuk mengkomunikasikan secara intensif kepada konsumen mengenai kekhususan kualitas dan produk jasa. (3) An effect-creating medium baju seragam yang berwarna, bercorak, suara dan desain untuk menciptakan sesuatu yang lain dari produk jasa yang ditawarkan.

\section{Kepuasan Konsumen}

Kepuasan dapat diartikan sebagai upaya pemenuhan sesuatu atau membuat sesuatu memadai (Tjiptono, 2011). Kepuasan konsumen merupakan salah satu tujuan yang penting dari sebuah bisnis. 
Kepuasan ini dapat diartikan sebagai perbandingan antara harapan yang diinginkan oleh konsumen dengan kenyataan yang dirasakan oleh konsumen itu sendiri atas suatu produk atau jasa yang ia gunakan.

Memuaskan kebutuhan konsumen adalah keinginan dari setiap perusahaan. Selain menjadi faktor penting bagi kelangsungan hidup perusahaan, memuaskan kebutuhan konsumen dapat meningkatkan keunggulan dan perbedaan dalam persaingan. Pelanggan atau konsumen yang sudah merasa puas terhadap produk atau jasa pelayanan akan cenderung untuk membeli produk barang atau menggunakan kembali jasa pada saat kebutuhan yang sama muncul dikemudian hari. Hal ini dapat diartikan bahwa kepuasan merupakan faktor kunci bagi konsumen dalam melakukan pembelian ulang yang merupakan tujuan untuk mencapai volume penjualan perusahaan.

\section{Hipotesis}

H1 : Bahwa variabel people, process dan physical evidence secara simultan berpengaruh signifikan terhadap kepuasan konsumen dalam penggunaan jasa transportasi KRL Commuter Line.

H2 : Bahwa variabel people, process dan physical evidence secara parsial berpengaruh signifikan terhadap kepuasan konsumen dalam penggunaan jasa transportasi KRL Commuter Line.

H3 : Dari ketiga variabel people, process dan physical evidence, variabel people adalah variabel yang paling dominan terhadap kepuasan konsumen dalam penggunaan jasa transportasi KRL Commuter Line.

\section{METODE PENELITIAN}

Jenis Penelitian ini adalah penelitian deskriptif dan verifikatif. Penelitian ini dilaksanakan di Kabupaten Karawang dengan periode pengamatan dalam penelitian ini pada bulan september sampai dengan desember 2019. Sampel diambil dari konsumen pengguna jasa transportasi KRL Commuter Line. Hair (1995), merekomendasikan bahwa jumlah sampel minimal adalah 5 kali dari jumlah item pertanyaan yang terdapat dikuesioner. Indikator dalam penelitian ini terdiri dari 3 variabel bebas dan 1 variabel terikat. Total pertanyaan dalam penelitian ini adalah 28 pertanyaan, sehingga minimal ukuran sampel penelitian ini adalah 28 x $5=140$. Teknik pengambilan sampling menggunakan NonProbability Sampling dengan Proporsional Purposive Sampling.

Untuk mendukung dalam pelaksanaan penelitian ini, ditinjau dari sumbernya data penelitian dibagi menjadi dua jenis yaitu bahan yang dipergunakaan berupa data primer dan data sekunder yang berhubungan dengan objek penelitian. Dalam pengumpulan data, digunakan beberapa teknik, yaitu: 1) Kuesioner adalah sejumlah pertanyaan tertulis yang diperlukan untuk memperoleh informasi dari responden., 2) Dokumen adalah teknik pengumpulan data dengan cara mempelajari, berbagai dokumen resmi, seperti data, buku-buku yang memiliki referensi yang jelas dengan masalah yang diamati. Skala pengukuran yang digunakan dalam kuesioner ini adalah Skala Likert dengan menggunakan rentang skor 1 - 5. Alat analisis penelitian ini adalah regresi dengan memanfaatkan program SPSS.

Variabel dalam penelitian ini terdiri dari variabel bebas $(\mathrm{X})$ dan variabel terikat $(\mathrm{Y})$. variabel bebas (independent) terdiri dari: people (X1), process (X2), physical evidence (X3) dan variabel terikat dalam penelitian ini adalah Kepuasan Konsumen (Y)

\section{HASIL DAN ANALISIS}

\section{Demografi Responden Penelitian}

Penelitian ini melibatkan 140 responden sebagai sampel penelitian. Peneliti menghimpun responden yang seluruhnya adalah konsumen pengguna jasa transportasi KRL Commuter Line, terdiri dari berbagai kalangan jenis kelamin, usia, pendidikan terakhir, pekerjaan, penghasilan perbulan dengan gambaran demografi (Tabel 1). 
Tabel 1. Demografi Responden

\begin{tabular}{|c|c|c|c|}
\hline \multicolumn{2}{|c|}{ Aspek Demografi Responden } & \multirow{2}{*}{$\begin{array}{c}\text { Frekuensi } \\
58\end{array}$} & \multirow{2}{*}{$\begin{array}{c}\text { Persentase (\%) } \\
41.4\end{array}$} \\
\hline Jenis Kelamin & Laki-laki & & \\
\hline & Perempuan & 82 & 58.6 \\
\hline \multirow[t]{3}{*}{ Usia } & $<20$ Tahun & 47 & 33.6 \\
\hline & 20 - 25 Tahun & 81 & 57.9 \\
\hline & $>25$ Tahun & 12 & 8.6 \\
\hline \multirow[t]{4}{*}{ Pendidikan } & SD & 1 & 0.7 \\
\hline & SMP & 1 & 0.7 \\
\hline & SMA/SMK & 119 & 85.0 \\
\hline & Perguruan Tinggi & 19 & 13.6 \\
\hline \multirow[t]{5}{*}{ Pekerjaan } & Pelajar/Mahasiswa & 115 & 82.1 \\
\hline & Pegawai Swasta & 10 & 7.1 \\
\hline & PNS & 4 & 2.9 \\
\hline & Wirausaha & 5 & 3.6 \\
\hline & Lain-lain & 6 & 4.3 \\
\hline \multirow{3}{*}{$\begin{array}{c}\text { Penghasilan } \\
\text { Perbulan }\end{array}$} & $<$ Rp. 500.000 & 93 & 66.4 \\
\hline & $\begin{array}{c}\text { Rp. } 500.000-\text { Rp. } \\
2.000 .000\end{array}$ & 22 & 15.7 \\
\hline & > Rp. 2.000 .000 & 25 & 17.9 \\
\hline
\end{tabular}

Sumber: Data diolah (2019)

\section{Deskripsi Statistik Variabel Penelitian}

Tabel 2 menunjukkan gambaran seberapa baik people, process, physical evidence dan kepuasan konsumen menurut responden secara umum. Peneliti menggolongkan nilai rata-rata jawaban responden pada masing-masing variable ke dalam 5 kategori berdasarkan kriteria, sebagai berikut: (1) skor rata-rata yang berada pada rentang 140 - 252 adalah Sangat Tidak Setuju, (2) skor rata-rata yang berada pada rentang 252,1 - 364 adalah Tidak Setuju, (3) skor rata-rata yang berada pada rentang 364,1 - 476 adalah Cukup Setuju, (4) skor rata-rata yang berada pada rentang 476,1 588 adalah Setuju, dan (5) skor rata-rata yang berada pada rentang 588,1 - 700 adalah Sangat Setuju

Tabel 2. Deskripsi Variabel Penelitian

\begin{tabular}{ccc}
\hline Variabel Penelitian & Rata-rata skor & Kategori \\
\hline People & 553,8 & Setuju \\
\hline Process & 521,1 & Setuju \\
\hline Physical Evidence & 511,4 & Setuju \\
\hline Kepuasan Konsumen & 531,4 & Setuju \\
\hline
\end{tabular}

Sumber: Data diolah (2019)

Berdasarkan tabel 2 diperoleh rata-rata skor untuk setiap variabel berada pada kategori setuju. Hal ini menunjukkan bahwa setiap variabel memiliki gambaran yang baik dimata konsumen secara umum.

\section{Pengujian Validitas}

Adapun hasil dari pengujian mengenai besaran tingkat validitas keempat variabel dalam setiap dimensi dan pertanyaan pada kuesioner dilihat pada tabel berikut: 
Tabel 3. Hasil Pengujian validitas

\begin{tabular}{ccccc}
\hline Variabel & Indikator & r Hitung & r Kritis & Kriteria \\
\hline \multirow{5}{*}{ People } & $\mathrm{X}_{1} \mathrm{P}_{1}$ & 0,569 & 0,3 & Valid \\
& $\mathrm{X}_{1} \mathrm{P}_{2}$ & 0,483 & 0,3 & Valid \\
& $\mathrm{X}_{1} \mathrm{P}_{3}$ & 0,539 & 0,3 & Valid \\
& $\mathrm{X}_{1} \mathrm{P}_{4}$ & 0,702 & 0,3 & Valid \\
& $\mathrm{X}_{1} \mathrm{P}_{5}$ & 0,589 & 0,3 & Valid \\
& $\mathrm{X}_{1} \mathrm{P}_{6}$ & 0,515 & 0,3 & Valid \\
& $\mathrm{X}_{1} \mathrm{P}_{7}$ & 0,622 & 0,3 & Valid \\
\hline \multirow{5}{*}{ Process } & $\mathrm{X}_{2} \mathrm{P}_{1}$ & 0,486 & 0,3 & Valid \\
& $\mathrm{X}_{2} \mathrm{P}_{2}$ & 0,404 & 0,3 & Valid \\
& $\mathrm{X}_{2} \mathrm{P}_{3}$ & 0,507 & 0,3 & Valid \\
& $\mathrm{X}_{2} \mathrm{P}_{4}$ & 0,670 & 0,3 & Valid \\
& $\mathrm{X}_{2} \mathrm{P}_{5}$ & 0,717 & 0,3 & Valid \\
& $\mathrm{X}_{2} \mathrm{P}_{6}$ & 0,729 & 0,3 & Valid \\
& $\mathrm{X}_{2} \mathrm{P}_{7}$ & 0,647 & 0,3 & Valid \\
\hline \multirow{5}{*}{ Physical } & $\mathrm{X}_{3} \mathrm{P}_{1}$ & 0,318 & 0,3 & Valid \\
& $\mathrm{X}_{3} \mathrm{P}_{2}$ & 0,672 & 0,3 & Valid \\
& $\mathrm{X}_{3} \mathrm{P}_{3}$ & 0,507 & 0,3 & Valid \\
& $\mathrm{X}_{3} \mathrm{P}_{4}$ & 0,621 & 0,3 & Valid \\
& $\mathrm{X}_{3} \mathrm{P}_{5}$ & 0,716 & 0,3 & Valid \\
& $\mathrm{X}_{3} \mathrm{P}_{6}$ & 0,630 & 0,3 & Valid \\
& $\mathrm{X}_{3} \mathrm{P}_{7}$ & 0,758 & 0,3 & Valid \\
\hline & $\mathrm{YKK}_{1}$ & 0,634 & 0,3 & Valid \\
& $\mathrm{YKK}_{2}$ & 0,499 & 0,3 & Valid \\
Kepuasan & $\mathrm{YKK}_{3}$ & 0,653 & 0,3 & Valid \\
& $\mathrm{YKK}_{4}$ & 0,481 & 0,3 & Valid \\
& $\mathrm{YKK}_{5}$ & 0,517 & 0,3 & Valid \\
& $\mathrm{YKK}_{6}$ & 0,673 & 0,3 & Valid \\
& $\mathrm{YKK}_{7}$ & 0,544 & 0,3 & Valid \\
\hline & & & &
\end{tabular}

Sumber: Hasil Pengolahaan SPSS (2019)

Pada Tabel 3. Menunjukkan bahwa uji validitas semua variabel dengan $n=140$ memiliki nilai $r$ hitung diatas 0,3 atau $r$ hitung $>r$ kritis. Maka semua pertanyaan pada kuesioner setiap variabel dinyatakan valid.

\section{Pengujian Reliabilitas}

Teknik yang digunakan untuk uji reliabilitas menggunakan koefisien alpha Cronbach. Untuk menilai suatu kuesioner dapat dikatakan reliabel/handal jika mempunyai koefisien korelasi lebih dari 0,6 (Sugiyono : 2012). Hasil uji reliabilitas untuk kuesioner pada masing-masing variabel dapat dilihat pada Tabel 4. berikut:

Tabel 4. Hasil Pengujian Reliabilitas

\begin{tabular}{lccc}
\hline \multicolumn{1}{c}{ Variabel } & $\begin{array}{c}\text { r Hitung } \\
\text { (Cronbach's } \\
\text { Alpha) }\end{array}$ & r Tabel & Kriteria \\
\hline People & 0,825 & 0,6 & Reliabel \\
Process & 0,840 & 0,6 & Reliabel \\
Physical Evidence & 0,843 & 0,6 & Reliabel \\
Kepuasan Konsumen & 0,824 & 0,6 & Reliabel \\
\hline Sumber : Hasil Pengolahan Data SPSS, 2019 & &
\end{tabular}

Berdasarkan Tabel 4. menunjukkan bahwa reliabilitas variabel People sebesar 0,825, tingkat reliabilitas pada variabel Process memiliki tingkat reliabilitas sebesar 0,840 , tingkat reliabilitas pada 
variabel Physical Evidence memliki tingkat reliabilitas sebesar 0,843, dan variabel Kepuasan Konsumen memiliki tingkat reliabilitas sebesar 0,824. Keempat variabel tersebut dinyatakan reliabel karena mempunyai $r$ Hitung $>r$ Tabel.

\section{Pengujian Normalitas}

Uji normalitas digunakan untuk mengetahui apakah suatu data terdistribusi normal atau mengikuti sebaran normal serta sesuai dengan standar yang ada ataupun tidak dengan menggunakan uji Kolmogorov-Smirnov.

Tabel 5. Hasil Pengujian Normalitas

\begin{tabular}{lcccc}
\hline \multicolumn{1}{c}{ Variabel } & n & Z & Sig. & Keterangan \\
\hline People (X1) & 140 & 0,904 & 0,386 & Normal \\
Process (X2) & 140 & 0,905 & 0,387 & Normal \\
Physical Evidence (X3) & 140 & 0,701 & 0,709 & Normal \\
Kepuasan Konsumen (Y) & 140 & 1,154 & 0,140 & Normal \\
Residual & 140 & 0,894 & 0,401 & Normal \\
\hline
\end{tabular}

Sumber : Hasil Pengolahan Data SPSS, 2019

Berdasarkan Tabel 4. , menunjukkan bahwa nilai signifikansi (Sig.) semua variabel mengikuti sebaran data normal karena nilai signifikan $\alpha$ hitung lebih besar dari $\alpha$ kritis yaitu 0,05 . Maka semua variabel mengikuti distribusi normal.

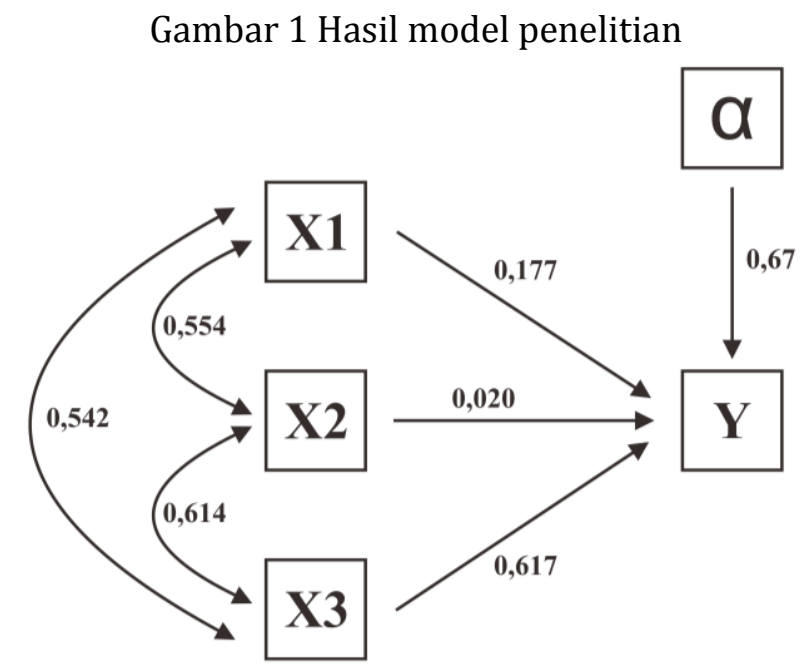

Sumber: Data diolah (2019)

Hubungan antara variabel People dan Process

Hubungan antara People dan Process memiliki nilai koefisien korelasi sebesar 0,554 dan mempunyai tingkat hubungan yang cukup kuat dan searah karena nilai positif dan berada pada interval koefisien 0,40 - 0,599 dengan kategori yang cukup kuat.

Hubungan antara variabel People dan Physical Evidence

Hubungan antara People dan Physical Evidence memiliki nilai koefisien korelasi sebesar 0,542 dan mempunyai tingkat hubungan yang cukup kuat dan searah karena nilai positif dan berada pada interval koefisien 0,40 - 0,599 dengan kategori yang cukup kuat.

Hubungan antara variabel Process dan Physical Evidence 
Hubungan antara Process dan Physical Evidence memiliki nilai koefisien korelasi sebesar 0,614 dan mempunyai tingkat hubungan yang kuat dan searah karena nilai positif dan berada pada interval koefisien 0,60 - 0,799 dengan kategori yang kuat.

Tabel 6. Pengaruh parsial variabel bebas terhadap terikat

\begin{tabular}{c|c|c|c|c}
\hline Structural & Sig. & A & t hitung & t table \\
\hline pyx1 & 0,016 & 0,05 & 2,444 & 1,656 \\
\hline pyx2 & 0,791 & 0,05 & 0,265 & 1,656 \\
\hline pyx3 & 0,000 & 0,05 & 8,060 & 1,656 \\
\hline
\end{tabular}

Sumber : Hasil Pengolahan Data SPSS, 2019

Pengaruh people terhadap kepuasan konsumen

Hipotesis diterima karena pada tabel 6 nilai t hitung untuk pengaruh variabel people terhadap kepuasan konsumen adalah lebih besar dari nilai t tabel yaitu $(2,444)>t$ tabel $(1,656)$.

Pengaruh process terhadap kepuasan konsumen

Hipotesis ditolak karena pada tabel 6 nilai t hitung untuk pengaruh variabel process terhadap kepuasan konsumen adalah kurang dari nilai t tabel yaitu $(0,265)<t$ tabel $(1,656)$.

Pengaruh physical evidence terhadap kepuasan konsumen

Hipotesis diterima karena pada tabel 6 nilai t hitung untuk pengaruh variabel physical evidence terhadap kepuasan konsumen adalah lebih besar dari nilai $t$ tabel yaitu $(8,060)>t$ tabel $(1,656)$.

Tabel 7. Pengaruh simultan variabel bebas terhadap variabel terikat

\begin{tabular}{ccccc}
\hline Structural & Sig. & A & f hitung & f table \\
\hline Pyx $1 \times 2 \times 3$ & 0,000 & 0,05 & 55,528 & 2,67
\end{tabular}

Sumber : Hasil Pengolahan Data SPSS, 2019

Pengaruh people, process dan physical evidence terhadap kepuasan konsumen

Hipotesis diterima karena pada tabel 7 nilai $\mathrm{f}$ hitung untuk pengaruh variabel people, process dan physical evidence terhadap kepuasan konsumen adalah lebih besar dari nilai $\mathrm{f}$ tabel yaitu $(55,528)>\mathrm{f}$ tabel $(2,67)$.

\section{Pembahasan Hipotesis}

\section{Pengaruh people terhadap kepuasan konsumen}

Hasil penelitian menunjukkan pengaruh people terhadap kepuasan konsumen adalah lebih besar nilai $\mathrm{t}$ hitung dari nilai $\mathrm{t}$ tabel yaitu $(2,444)>\mathrm{t}$ tabel $(1,656)$. Dengan pengaruh people terhadap kepuasan konsumen hasil dari pengolahan data memiliki nilai sebesar 0,177 atau 17,7\%.

\section{Pengaruh process terhadap kepuasan konsumen}

Hasil penelitian menunjukkan pengaruh process terhadap kepuasan konsumen kurang dari nilai t tabel yaitu $(0,265)<t$ tabel $(1,656)$. Dengan pengaruh process terhadap kepuasan konsumen hasil dari pengolahan data memiliki nilai sebesar 0,020 atau $2 \%$.

\section{Pengaruh physical evidence terhadap kepuasan konsumen}

Hasil penelitian menunjukkan pengaruh physical evidence terhadap kepuasan konsumen adalah lebih besar nilai t hitung dari nilai t tabel yaitu $(8,060)>t$ tabel $(1,656)$. Dengan pengaruh physical evidence terhadap kepuasan konsumen hasil dari pengolahan data memiliki nilai sebesar 0,617 atau 61,7\%. 
Karena pengaruh parsial variabel Physical Evidence $\left(\mathrm{X}_{3}\right)$ lebih besar dari variabel People $\left(\mathrm{X}_{1}\right)$ dan Process $\left(\mathrm{X}_{2}\right)$ maka dapat dinyatakan bahwa variabel Physical Evidence $\left(\mathrm{X}_{3}\right)$ lebih banyak memberikan kontribusi terhadap Kepuasan Konsumen $(\mathrm{Y})$ dibandingkan variabel People $\left(\mathrm{X}_{1}\right)$ dan Process $\left(\mathrm{X}_{3}\right)$. Hal ini disebabkan karena responden lebih memilih menilai bagaimana keadaan dan kondisi yang terdapat pada stasiun maupun gerbong kereta dibandingkan para petugas yang bekerja dan prosedur yang terdapat pada PT Kereta Commuter Indonesia.

Pengaruh people, process dan physical evidence terhadap kepuasan konsumen

Pengaruh simultan people, process dan physical evidence terhadap kepuasan konsumen, dengan kriteria uji sig. $(0,000)<\alpha(0,05)$ dan f hitung $(55,528)>\mathrm{f}$ tabel $(2,67)$ maka Ho ditolak. Total pengaruh people, process dan physical evidence terhadap kepuasan konsumen sebesar 0,551 atau $55,1 \%$ berarti variabel kepuasan konsumen $(\mathrm{Y})$ dapat diterangkan oleh people $\left(\mathrm{X}_{1}\right)$, process $\left(\mathrm{X}_{2}\right)$ dan physical evidence $\left(\mathrm{X}_{3}\right)$ atau dapat diartikan bahwa people $\left(\mathrm{X}_{1}\right)$, process $\left(\mathrm{X}_{2}\right)$ dan physical evidence $\left(\mathrm{X}_{3}\right)$ memiliki kontribusi terhadap kepuasan konsumen $(\mathrm{Y})$ sebesar 55,1\% sedangkan sisanya $100-55,1=$ $44,9 \%$ merupakan kontribusi variabel lainnya $(\epsilon)$ yang tidak di teliti dalam penelitian ini.

\section{KESIMPULAN}

Berdasarkan hasil penelitian yang telah dilakukan menggunakan analisis deskriptif dan verifikatif maka berdasarkan penelitian tersebut dapat diambil kesimpulan sebagai berikut:

1. Gambaran variabel people yang diukur melalui dimensi keterampilan dan sikap. Rata-rata skor tertinggi terdapat pada dimensi keterampilan. Hal ini menunjukkan adanya penilaian baik dari responden mengenai keterampilan yang dimiliki oleh petugas administrasi maupun petugas jaga yang membuat konsumen merasa puas. Sedangkan rata-rata skor terendah terdapat pada dimensi sikap.

2. Gambaran variabel process diukur melalui dimensi prosedur, mekanisme dan aliran aktifitas. Rata-rata skor tertinggi terdapat pada dimensi prosedur. Hal ini menunjukkan adanya penilaian baik dari responden mengenai prosedur yang diterapkan di setiap stasiun kereta commuter membuat konsumen merasa puas. Sedangkan rata-rata skor terendah terdapat pada dimensi aliran aktifitas.

3. Gambaran variabel physical evidence diukur melalui dimensi keadaan dan kondisi. Rata-rata skor tertinggi terdapat pada dimensi kondisi. Hal ini menunjukkan adanya penilaian baik dari responden mengenai kondisi yang terjadi saat responden sedang menggunakan jasa transportasi tersebut yang membuat konsumen merasa puas. Sedangkan rata-rata skor terendah terdapat pada dimensi keadaan.

4. Gambaran variabel kepuasan konsumen diukur melalui dimensi kepuasan pelanggan keseluruhan, dimensi kepuasan pelanggan, kesesuaian harapan, minat pembelian ulang, kesediaan untuk merekomendasi dan ketidakpuasan pelanggan. Rata-rata skor tertinggi terdapat pada dimensi kesesuaian harapan. Hal ini menunjukkan adanya penilaian baik dari responden mengenai apapun yang menjadi harapan responden dalam menggunakan jasa transportasi yang kemudian sesuai dengan apa yang diinginkan sehingga membuat konsumen merasa puas. Sedangkan rata-rata skor terendah terdapat pada dimensi ketidakpuasan pelanggan.

5. Terdapat pengaruh positif people, process dan physical evidence terhadap kepuasan konsumen. Hal ini terbukti dengan hasil uji simultan (Uji F) dan uji parsial ( Uji t) sebagai berikut:

a. Hasil uji simultan menunjukkan bahwa variabel independen (people, process dan physical evidence) berpengaruh signifikan terhadap terhadap variabel dependen (kepuasan konsumen) yaitu nilai sig. F $<$ sig. $\alpha$ dan hasil koefisien determinasi (Adjusted R Square) secara simultan menunjukkan nilai $\mathrm{R}^{2}$ sebesar sebesar 0.551 artinya 55,1\% kepuasan konsumen $(\mathrm{Y})$ dapat dijelaskan oleh people $\left(\mathrm{X}_{1}\right)$, process $\left(\mathrm{X}_{2}\right)$ dan physical evidence $\left(\mathrm{X}_{3}\right)$. Sedangkan sisanya sebesar $44,9 \%$

b. dijelakan oleh variabel-variabel lain yang tidak diteliti dalam penelitian ini. 
c. Hasil uji parsial menunjukkan yang paling berkontribusi mempengaruhi kepuasan konsumen secara signifikan atau nyata pada PT Kereta Commuter Indonesia adalah physical evidence, yaitu dengan nilai 0,617 atau 61,7\%.

\section{SARAN}

\section{Saran Bagi Perusahaan}

Setelah penulis memberikan kesimpulan dari hasil penelitian tentang pengaruh people, process dan physical evidence terhadap kepuasan konsumen PT Kereta Commuter Indonesia, maka penulis akan memberikan beberapa saran yang mungkin dapat digunakan oleh PT Kereta Commuter Indonesia sebagai berikut:

1. Untuk meningkatkan kepuasan konsumen, maka perusahaan harus memperhatikan masalah sikap petugas yang kurang dalam penilaian konsumen karena sikap akan memberikan pengaruh secara langsung terhadap penilaian kepuasan konsumen.

2. Keterlambatan kedatangan maupun keberangkatan kereta yang dinyatakan terbilang sering terjadi, penulis menyarankan agar jadwal yang telah diberikan oleh pihak penyedia jasa dapat berjalan sebagaimana mestinya sehingga memudahkan para konsumen untuk melakukan kegiatan lain sesuai pada waktunya

3. Pada perusahaan agar konsumen merasa puas terhadap pelayanan yang diberikan jasa transportasi kereta commuter ini maka hal yang harus dilakukan adalah dengan memberikan tanggapan yang cepat terhadap segala macam komplain, keluhan maupun saran dari konsumen agar konsumen merasa mereka diprioritaskan sebagai pengguna jasa.

\section{Saran kepada Peneliti Selanjutnya}

Hasil penelitian ini diharapkan mampu membantu peneliti selanjutnya untuk dijadikan acuan pada penelitian selanjutnya. Diharapkan peneliti selanjutnya dapat melakukan penelitian lanjutan untuk mencari tahu pengaruh people, process dan physical evidence terhadap variabel dependen lainnya. Hasil penelitian ini menyatakan bahwa pengaruh people, process dan physical evidence terhadap kepuasan konsumen sebesar 55,1\%, hasil ini yang mendasari peneliti untuk memberikan rekomendasi terhadap peneliti selanjutnya untuk meneliti people, process dan physical evidence dengan tambahan dimensi lain dari penelitian ini.

\section{DAFTAR PUSTAKA}

Badan Pusat Statistik. (2018). Jumlah Penumpang Kereta Api Menurut Wilayah (2006-Juli 2018). Jakarta (ID) : Badan Pusat Statistik.

Badan Pusat Statistik. (2019). Pertumbuhan Jumlah Penumpang Kereta Api Januari-Juli 2019. Jakarta (ID) : PT Kereta Api Indonesia dan PT. KAI Commuter Jabodetabek

Badan Pusat Statistik. (2018). Grafik Jumlah Pengunjung KRL Commuter Line 2006-2018. Jakarta (ID) : Badan Pusat Statistik

Billy Tantra, Jessica Marcelina. (2017). Pengaruh Marketing Mix (7P) Terhadap Keputusan Pembelian Pada Guest House di Surabaya. Jurnal Hospitality dan Manajemen Jasa 5 (2).

Christianto Irawan, Michael Loekito. (2014). Analisa Pengaruh Marketing Mix (7P) Terhadap Keputusan Pembelian di Folks! Coffee shop and Tea House Surabaya. Jurnal Hospitality dan Manajemen Jasa 2 (1), 86-100

Hair, J. F., Black, W. C., Babin, B. J., Anderson, R. E. (2010). Multivariate Data Analysis: A Global Perspective (7th ed.). New Jersey: Pearson Education, Inc. 
Kusumasitta. (2014). Relevansi Dimensi Kualitas Pelayanan dan Kepuasan Pelanggan Bagi Pengunjung Museum di Taman Mini Indonesia Indah. Jurnal Manajemen dan Pemasaran Jasa Vol. 7, No. 1.

Kotler, P., dan Keller, K. (2011). Manajemen Pemasaran. Indeks: Jakarta.

Lovelock, C.,dan Wright, K. (2011). Manajemen Pemasaran Jasa. PT INDEKS Gramedia Group: Jakarta.

Prasojo, Lanang Akbar. (2015). Kualitas Pelayanan PT. Kereta Api Indonesia Daop VIII Stasiun Gubeng (Studi pada Layanan Fasilitas Mesin Cetak Tiket Mandiri). E-Journal Universitas Negeri Semarang Vol. 3, No. 7, 1-16

Ricky Wibowo, Edwin Japarianto. (2013). Pengaruh Retail Mix Terhadap Minat Beli di Keraton Departemen Store. Jurnal Manajemen Pemasaran Vol. 1, No. 1, 1-12.

Ryan N., Edwin Japarianto. (2013). Pengaruh People, Physical Evidence, Product, Promotion, Price, dan Place Terhadap Tingkat Kunjungan di Kafe Coffee Cozies Surabaya. Jurnal Manajemen Pemasaran Petra Vol. 1, No. 2, $1-9$.

Sugiyono. (2012). metode Penelitian Kuantitatif, Kualitatif dan R\&D. Bandung: Alfabeta

Suri Amilia, Ayu Novianti. (2016). Pengaruh Buaran Pemasaran Terhadap Kepuasaan Konsumen Pada Warung Kanasha di Kota Langsa. Jurnal Manajemen dan Keuangan Vol. 5, No 1.

Tjiptono, F. (2011). Pemasaran Jasa. Malang: Bayumedia.

Wijaya, Tony. (2011). Manajemen Kualitas Jasa Desain Servqual, QFD, dan Kano Disertasi Contoh Aplikasi dalam Kasus Penelitian. Jakarta: Indeks.

Yamit, Zulian. (2013). Manajemen Kualitas Produk \& jasa. Yogyakarta: Ekonisia. 